\title{
Soluble Urokinase-Type Plasminogen Activator Receptor and Arterial Stiffness in Patients with COPD
}

\author{
Renáta M. Böcskei ${ }^{1}$ (1) $\cdot$ Béla Benczúr ${ }^{2} \cdot$ György Losonczy $^{1}$ (1) $\cdot$ Miklós Illyés $^{3} \cdot$ Attila Cziráki $^{3} \cdot$ Veronika Müller $^{1}$ (D) \\ Anikó Bohács ${ }^{1} \cdot$ András Bikov $^{1}$ (i)
}

Received: 15 December 2018 / Accepted: 18 February 2019 / Published online: 28 February 2019

(c) The Author(s) 2019

\begin{abstract}
Introduction Soluble urokinase-type plasminogen activator receptor (suPAR) is upregulated by inflammation and plays a role in the pathogenesis of atherosclerosis. Chronic obstructive pulmonary disease (COPD) is associated with enhanced systemic inflammation and increased risk for atherosclerosis, however, studies analysing the circulating suPAR levels in COPD are contradictory. The aim of the study was to investigate plasma suPAR concentrations together with markers of arterial stiffness in COPD.

Materials and Methods Twenty-four patients with COPD and 18 non-COPD, control subjects participated in the study. Plasma suPAR was measured, together with lung volumes, symptom burden, exacerbation history, markers of arterial stiffness and soluble inflammatory biomarkers, such as endothelin-1, high-sensitivity C-reactive protein (hsCRP), interleukin-6 (IL-6). Results Plasma suPAR levels were higher in COPD $(2.84 \pm 0.67 \mathrm{ng} / \mathrm{ml}$ vs. $2.41 \pm 0.57 \mathrm{ng} / \mathrm{ml}, p=0.03)$ and were related to lung function measured with $\mathrm{FEV}_{1}(r=-0.65, p<0.01)$ and symptom burden determined with the modified Medical Research Council questionnaire $(r=0.55, p<0.05)$. Plasma suPAR concentrations correlated with various measures of arterial stiffness in all subjects, but only with ejection duration in COPD $(r=-0.44, p=0.03)$.

Conclusions Plasma suPAR levels are elevated in COPD and relate to arterial stiffness. Our results suggest that suPAR may be a potential link between COPD and atherosclerosis.
\end{abstract}

Keywords COPD $\cdot$ SuPAR $\cdot$ IL-6 $\cdot$ Arterial stiffness $\cdot$ Cardiovascular risk

\section{Introduction}

Chronic obstructive pulmonary disease (COPD) is a chronic, progressive disorder of the airways and lung parenchyma and is one of the leading causes of mortality worldwide [1]. Chronic exposure to noxious particles, especially to smoking induces airway inflammation which eventually leads to mucus hypersecretion, emphysema and small airway narrowing [2]. COPD is also associated with small-grade systemic inflammation which may be a potential link to cardiovascular comorbidities, such as atherosclerosis [3-5].

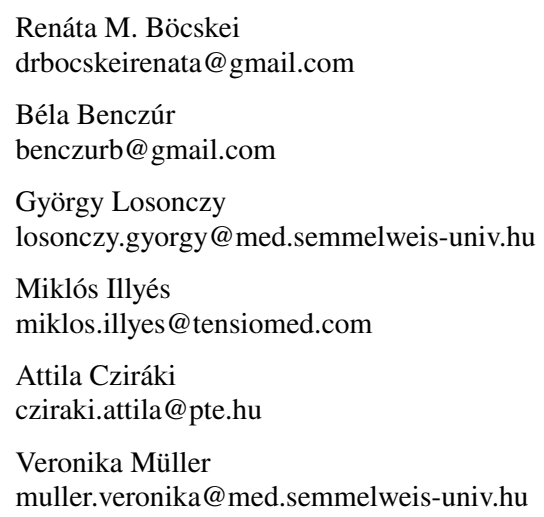

Anikó Bohács

bohacsdr@gmail.com

András Bikov

andras.bikov@gmail.com

1 Department of Pulmonology, Semmelweis University, Diós árok Street. 1/c, Budapest 1125, Hungary

2 1st Dept of Internal Medicine (Cardiology/Nephrology), Balassa Janos County Hospital, Béri Balogh Ádám Street 5-7, Szekszárd 7100, Hungary

3 Heart Institute, Faculty of Medicine, University of Pécs, Ifjúság Street 13, Pecs 7624, Hungary 
However, the elements of systemic inflammation are poorly described in COPD.

Soluble urokinase-type plasminogen activator receptor (suPAR) is a soluble form of the urokinase plasminogen activator receptor (UPAR) that is produced upon cleavage of membrane-bound UPAR. It is found in various body fluids, including blood, urine and cerebrospinal fluid [6-8]. It is expressed by endothelial cells, macrophages, monocytes, neutrophils, lymphocytes and fibroblasts [9], and is upregulated by infections and pro-inflammatory cytokines [6]. The suPAR contributes to plasminogen activation, cell adhesion, chemotaxis and immune cell activation [10]. Clinical studies suggest that suPAR has an additive value to high-sensitivity C-reactive protein (hsCRP) or interleukin-6 (IL-6) in characterizing systemic inflammation in cardiovascular diseases [11].

So far, only few studies have investigated suPAR in COPD, mainly focusing on acute exacerbations and reporting elevated levels $[12,13]$. In stable disease, Can et al. reported higher serum suPAR levels compared to controls [14]. This contradicts a study by Wang et al. who did not find significant difference between COPD and those in a healthy condition [15]. The discrepancy may be due to the relatively mild disease severity of the latter study [15], as the former study assessed patients with a wider range of lung function [14]. In addition, a number of factors which characterize disease burden apart from lung function, including symptom burden, exacerbation history and arterial stiffness, has not been assessed.

The aim of the present study was, therefore, to compare circulating suPAR levels in COPD and health, and to correlate them with various characteristics of COPD. To study suPAR in the context of other inflammatory biomarkers we also analysed hsCRP, IL-6 and endothelin-1.

\section{Materials and Methods}

\section{Study subjects}

A total of 42 middle aged individuals ( $n=19$ males, mean age: $59 \pm 11$ years), were included in the study. Figure 1 displays the enrolment of participants into the study. COPD patients $(n=24)$ were recruited at stable state at the outpatient clinic of the Department of Pulmonology, Semmelweis University. COPD was diagnosed according to the Global Initiative for Chronic Obstructive Lung Disease (GOLD) criteria based on symptoms, suggestive history and postbronchodilator $\mathrm{FEV}_{1} / \mathrm{FVC}<0.70$ [1]. Patients were categorised into ABCD subgroups according to the 2017 GOLD criteria [1]. Exacerbations in the last 12 months were defined as episodes requiring an increase in inhaler use or need for addition of antibiotics and/or systemic steroids. Frequent exacerbator phenotype was defined as having $\geq 2$ exacerbations last year. None of the patients had suffered from acute exacerbation in the last 3 months. Control volunteers $(n=18)$ were recruited among co-workers at the Department of Pulmonology. Subjects with known cardiovascular disease, including coronary artery disease, cerebrovascular disease, or peripheral arterial disease and those who had diabetes mellitus were excluded. None of the study participants had an ongoing infection during the study.

\section{Study Design}

The study had a case-control, cross-sectional design. After obtaining written informed consent, medical history was taken, patients filled out the COPD Assessment Test (CAT) and modified Medical Research Council (mMRC) questionnaires, body plethysmography and arteriography were
Fig. 1 Flow chart of the number and selection of individuals in the study population

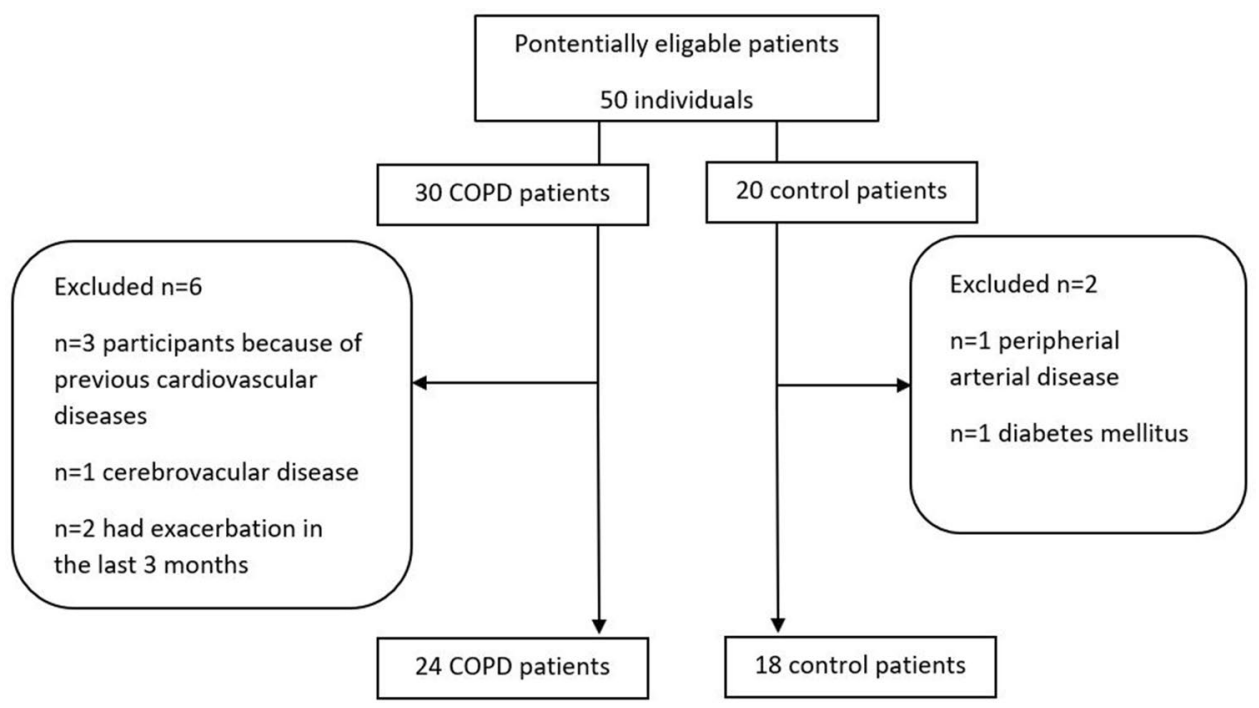


performed and arterialised capillary blood gases were measured. Venous blood was taken for total cholesterol, HDLcholesterol, LDL-cholesterol, triglyceride, hsCRP, IL-6, endothelin-1 and suPAR measurements.

The study has been approved by the Semmelweis University Ethics Committee (TUKEB 131/2017), and all participants gave their informed consent.

\section{Body Plethysmography}

Lung function tests and body plethysmography were carried out with the PDD-301/s device (Piston Ltd., Budapest, Hungary) according to the American Thoracic Society guidelines [16]. Lung function indices were calculated using the best of three technically acceptable measurements.

\section{Measurement of Arterial Stiffness and Blood Pressure}

Blood pressure parameters and arterial stiffness parameters, including aortic pulse wave velocity (PWVao) and Aortic Augmentation Index (Aix) measurements were performed in the supine position and after $10 \mathrm{~min}$ of rest using an invasively validated oscillometric, upper-arm cuff automatic device based on the 'occluded artery theory' (Arteriograph, TensioMed Ltd., Budapest, Hungary). Details of the method and its invasive validations have been published previously $[17,18]$. In brief, the device first measures the actual brachial systolic blood pressure (SBPbr) and brachial diastolic blood pressure (DBP) with a clinically validated algorithm [19]. The cuff is then inflated to a supra-systolic pressure (35-40 $\mathrm{mmHg}$ above the actual brachial systolic blood pressure) occluding the brachial artery completely. Pure pressure signals are collected by the cuff in this condition. The time difference between the early and late systolic peaks, is the return time (RT). By dividing the return time by 2 , the transit time of the aortic pulse wave is obtained. By measuring the jugulum to symphysis straight distance between the suprasternal notch and pubic bone (an acceptable estimate of the aortic length [20]), divided by transit time, the PWVao $(\mathrm{m} / \mathrm{s})$ can be calculated. The Augmentation Index (Aix) was calculated taking the differences between amplitudes of the forward and reflected systolic waves. The left ventricle ejection duration (ED) is calculated from the pulse waves, by measuring the time between the opening and closing of the aortic valve. The Arteriograph calculates the central blood pressure (SBPao) based on the brachial SBPbr and the pulse pressure curve. SBPao is the systolic blood pressure measured at the aortic root. The difference between the central and peripheral systolic pressure (SBPao-SBPbr) is called pressure amplification. At younger ages when the aortic wall is still elastic the SBPao is less than SBPbr on the upper arm.

\section{Circulating Biomarkers}

Plasma was isolated from EDTA anticoagulated fasting blood samples and stored at $-80{ }^{\circ} \mathrm{C}$ until measurement. Plasma suPAR concentrations were measured with the suPARnostic Flex ELISA assay (ViroGates A/S, Birkerød, Denmark) according to the manufacturers' instructions. Interleukin-6 levels were analysed by the Immulite 2000 immunoassay system (Siemens Healthcare GmbH, Erlangen, Germany). Plasma endothelin-1 levels were determined with the Endothelin (1-21) ELISA Kit (Biomedica, Medizinprodukte GmbH \& Co KG, Wien). The hsCRP levels were measured using commercially available tests (Roche Diagnostics GmbH, Mannheim, Germany). The technicians who measured the samples were blinded to the identity of the patient samples.

\section{Statistical Analysis}

GraphPad Prism 5.03 (GraphPad Software, La Jolla, CA, US) was used for statistical analysis. Data normality has been assessed with the Shapiro-Wilk test. COPD and control groups were compared with un-paired $t$ test, Mann-Whitney and Chi square tests. The relationships between plasma suPAR levels and clinical variables as well as circulating biomarkers were assessed with Pearson's and Spearman's tests. Data are expressed as mean \pm standard deviation for parametric and median/range/for non-parametric variables. A $p$ value $<0.05$ was considered significant.

The sample size was calculated to find a difference between COPD and control group with an effect size of 0.90 , power of 0.80 and an alpha of 0.05 [21]. These numbers were based on a distribution of plasma suPAR values [22]. Post hoc sensitivity analyses ensured it was possible to detect correlations between suPAR and clinical variables as well as other plasma biomarkers with an effect size of 0.54 ( -0.40 and 0.40 , minimal and maximal critical $r$ values), statistical power of 0.80 and alpha of 0.05 [21].

\section{Results}

\section{Comparison of COPD and Control Groups as Well as Ever- and Never-Smoker Controls}

Characteristics of the study population are presented in Table 1 . The levels of plasma suPAR were significantly higher in patients with COPD $(2.84 \pm 0.67 \mathrm{ng} / \mathrm{ml}$ vs. $2.41 \pm 0.57 \mathrm{ng} / \mathrm{ml}, \mathrm{p}=0.03$, Fig. 2).

Ever-smoker controls $(n=9)$ tended to have elevated plasma suPAR levels, and significantly increased PWVao as well as decreased RT, $\mathrm{FEV}_{1}$ and FVC compared to neversmokers. Comparison of smoker and non-smoker controls 
Table 1 Subjects' characteristics

\begin{tabular}{|c|c|c|c|}
\hline & $\operatorname{COPD}(n=24)$ & Controls $(n=18)$ & $p$ value \\
\hline Age (years) & $60.9 \pm 5.3$ & $58.4 \pm 6.5$ & 0.16 \\
\hline Gender (males\%) & $54 \%$ & $33 \%$ & 0.18 \\
\hline Smoker (ever/never) & $23 / 1$ & $9 / 9$ & $<\mathbf{0 . 0 1}$ \\
\hline Smoker (current/ex/never) & $9 / 14 / 1$ & $8 / 1 / 9$ & $<0.01$ \\
\hline Cigarette pack years & $33.9 \pm 18.2$ & $11.4 \pm 15.2$ & $<\mathbf{0 . 0 1}$ \\
\hline Number of frequent exacerbators & 12 & NA & NA \\
\hline $\mathrm{FEV}_{1}(1)$ & $1.43 \pm 0.67$ & $2.81 \pm 0.67$ & $<\mathbf{0 . 0 1}$ \\
\hline $\mathrm{FEV}_{1}(\%$ pred.) & $47.8 \pm 22.4$ & $101 \pm 19.9$ & $<\mathbf{0 . 0 1}$ \\
\hline FVC (1) & $2.7 \pm 0.83$ & $3.6 \pm 0.9$ & $<\mathbf{0 . 0 1}$ \\
\hline FVC (\% pred.) & $69.7 \pm 23.3$ & $107.6 \pm 18.2$ & $<0.01$ \\
\hline $\mathrm{FEV}_{1} / \mathrm{FVC}(\%)$ & $51.9 \pm 12.7$ & $78.2 \pm 3.9$ & $<\mathbf{0 . 0 1}$ \\
\hline $\mathrm{RV}(1)$ & $4.2 \pm 1.6$ & $2.2 \pm 0.8$ & $<\mathbf{0 . 0 1}$ \\
\hline TLC (1) & $7.3 \pm 1.8$ & $5.9 \pm 1.6$ & 0.018 \\
\hline RV/TLC (\%) & $57.3 \pm 11.9$ & $36.7 \pm 8.4$ & $<\mathbf{0 . 0 1}$ \\
\hline Raw $(\mathrm{kPa} * \mathrm{~s} / \mathrm{l})$ & $0.48 \pm 0.2$ & $0.28 \pm 0.1$ & $<0.01$ \\
\hline $\mathrm{pO}_{2}(\mathrm{mmHg})$ & $65.1 \pm 7.4$ & $76.8 \pm 8.1$ & $<\mathbf{0 . 0 1}$ \\
\hline $\mathrm{pCO}_{2}(\mathrm{mmHg})$ & $41.1 \pm 4.7$ & $38.9 \pm 2.7$ & 0.13 \\
\hline CAT & $18.5 \pm 7.2$ & $7.8 \pm 2.7$ & $<0.01$ \\
\hline $\mathrm{mMRC}$ & $1.8 \pm 0.8$ & $0.2 \pm 0.4$ & $<0.01$ \\
\hline Total cholesterol (mmol/l) & $5.4 \pm 0.8$ & $5.1 \pm 0.8$ & 0.42 \\
\hline Triglyceride (mmol/l) & $1.3 \pm 1.0$ & $1.9 \pm 1.5$ & 0.18 \\
\hline HDL-C (mmol/l) & $1.7 \pm 0.3$ & $1.4 \pm 0.25$ & 0.04 \\
\hline LDL-C (mmol/l) & $2.9 \pm 1.0$ & $3.0 \pm 0.5$ & 0.67 \\
\hline hsCRP (mg/l) & $2.50 / 0.50-7.80 /$ & $1.65 / 0.5-4.9 /$ & 0.14 \\
\hline IL-6 (pg/ml) & $4.29 / 2.61-13.63 /$ & $3.47 / 1.65-5.75 /$ & $\mathbf{0 . 0 3}$ \\
\hline suPAR (ng/ml) & $2.8 \pm 0.7$ & $2.4 \pm 0.6$ & $\mathbf{0 . 0 3}$ \\
\hline ED-1 (fmol/ml) & $1.3 / 0.0-10.1 /$ & $0.8 / 0.0-6.1 /$ & 0.18 \\
\hline
\end{tabular}

Data are expressed as mean \pm standard deviation or median/range/or percentage. Significant differences are highlighted in bold

$C O P D$ chronic obstructive pulmonary disease, $F E V_{1}$ forced expiratory volume in $1 \mathrm{~s}, F V C$ forced vital capacity, $R V$ residual volume, $T L C$ total lung capacity, Raw airway resistance, $C A T$ COPD Assessment Test, $m M R C$ Modified Medical Research Council Dyspnea Scale, $H D L-C$ high-density lipoprotein cholesterol, $L D L$ low-density lipoprotein cholesterol, $h s C R P$ high-sensitivity C-reactive protein, $I L-6$ interleukin-6, sUPAR soluble urokinase-type plasminogen activator receptor, $E D-1$ endothelin-1

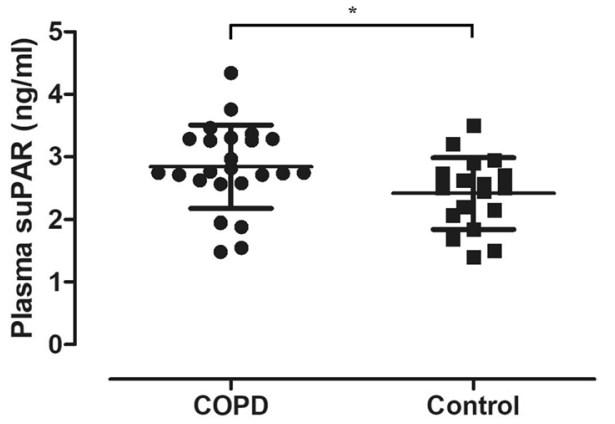

Fig. 2 Plasma suPAR levels in COPD and controls. Significantly higher plasma suPAR levels were detected in COPD $(* p=0.03)$. Individual data are presented with mean \pm standard deviation is presented in Table 2. There was a significant correlation between cigarette pack years and plasma suPAR levels in controls $(r=0.68, p<0.01)$.

\section{Relationship Between Circulating suPAR and Measures of COPD Severity and Activity}

There was a significant relationship between circulating suPAR levels and $\mathrm{FEV}_{1} \%(r=-0.65, p<0.01$, Fig. 3), $\mathrm{FEV}_{1} / \mathrm{FVC}(r=-0.46, p=0.02)$ and mMRC $(r=0.55$, $p<0.01$, Fig. 4). In addition, plasma suPAR levels tended to be elevated in patients with frequent exacerbations $(3.09 \pm 0.39 \mathrm{ng} / \mathrm{ml}$ vs. $2.58 \pm 0.79 \mathrm{ng} / \mathrm{ml}, p=0.058) . \mathrm{In}$ 
Table 2 Comparison of everand never-smokers

\begin{tabular}{|c|c|c|c|}
\hline & $\begin{array}{l}\text { Control } \\
\text { Never-smoker }(n=9)\end{array}$ & $\begin{array}{l}\text { Control } \\
\text { Ever-smoker }(n=9)\end{array}$ & $p$ value \\
\hline $\mathrm{FEV}_{1}(1)$ & $3.1 \pm 0.68$ & $2.5 \pm 0.54$ & 0.05 \\
\hline $\mathrm{FEV}_{1}(\%$ pred.) & $103.8 \pm 21.5$ & $99.3 \pm 19.9$ & 0.28 \\
\hline FVC (l) & $4.1 \pm 0.9$ & $3.2 \pm 0.7$ & 0.02 \\
\hline FVC (\% pred.) & $112.3 \pm 19.1$ & $102.9 \pm 17.0$ & 0.3 \\
\hline $\mathrm{FEV}_{1} / \mathrm{FVC}(\%)$ & $76.8 \pm 3.8$ & $79.6 \pm 3.7$ & 0.13 \\
\hline $\mathrm{RV}(1)$ & $2.56 \pm 0.9$ & $1.9 \pm 0.67$ & 0.17 \\
\hline TLC (1) & $6.8 \pm 1.8$ & $5.1 \pm 0.8$ & 0.11 \\
\hline RV/TLC (\%) & $37.1 \pm 6.3$ & $36.4 \pm 10.22$ & 0.74 \\
\hline Raw (kPa*s/l) & $0.26 \pm 0.8$ & $0.31 \pm 0.4$ & 0.27 \\
\hline hsCRP (mg/l) & $1.4 / 0.50-3.8 /$ & $1.9 / 0.7-4.9 /$ & 0.18 \\
\hline IL-6 (pg/ml) & $3.3 / 2.55-4.13 /$ & $3.7 / 1.65-5.75 /$ & 0.29 \\
\hline suPAR (ng/ml) & $2.1 \pm 0.5$ & $2.7 \pm 0.5$ & 0.08 \\
\hline ED-1 (fmol/ml) & $0.29 / 0.0-3.1 /$ & $1.17 / 0.3-6.1 /$ & 0.11 \\
\hline $\mathrm{SBPbr}(\mathrm{mmHg})$ & $129 \pm 11.1$ & $131 \pm 8.4$ & 0.76 \\
\hline $\mathrm{DBP}(\mathrm{mmHg})$ & $78 \pm 8.6$ & $76 \pm 6.4$ & 0.71 \\
\hline HR (min) & $67 \pm 8.6$ & $71 \pm 17.8$ & 0.52 \\
\hline $\mathrm{PP}(\mathrm{mmHg})$ & $51.1 \pm 6.9$ & $52.0 \pm 6.1$ & 0.78 \\
\hline SBPao (mmHg) & $122 / 98-142 /$ & $129 / 113-148 /$ & 0.71 \\
\hline SBPao-SBPbr (mmHg) & $-5 /-10$ to $2 /$ & $-1.1 /-11$ to $7 /$ & 0.18 \\
\hline Aix \% & $-12.2 \pm 23.6$ & $-2.6 \pm 33.0$ & 0.49 \\
\hline $\mathrm{ED}(\mathrm{ms})$ & $320.0 \pm 25.9$ & $321.1 \pm 33.1$ & 0.94 \\
\hline PWVao (m/s) & $8.1 \pm 0.9$ & $9.5 \pm 1.3$ & 0.03 \\
\hline RT (ms) & $127.7 \pm 15.8$ & $102.7 \pm 16.3$ & $<0.01$ \\
\hline
\end{tabular}

Data are expressed as mean \pm standard deviation or median/range/or percentage. Significant differences are highlighted in bold

$F E V_{1}$ forced expiratory volume in $1 \mathrm{~s}, F V C$ forced vital capacity, $R V$ residual volume, $T L C$ total lung capacity, Raw: airway resistance, $h s C R P$ high sensitivity C-reactive protein, $I L-6$ interleukin-6, suPAR soluble urokinase-type plasminogen activator receptor, $E D-1$ endothelin-1, $S B P b r$ brachial systolic blood pressure, $D B P$ brachial diastolic blood pressure, $H R$ heart rate, $P P$ pulse pressure, SBPao the central blood pressure, SBPao SBPbr pressure amplification, Aix Augmentation Index, ED ejection duration, $P W V a o$ aortic pulse wave velocity, $R T$ return time

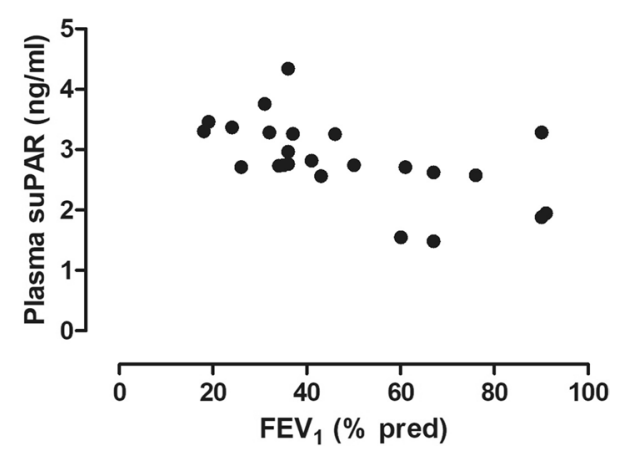

Fig. 3 Relationship between plasma suPAR levels and lung function. A significant relationship was detected between plasma suPAR levels and $\mathrm{FEV}_{1}(r=-0.65, p<0.01)$

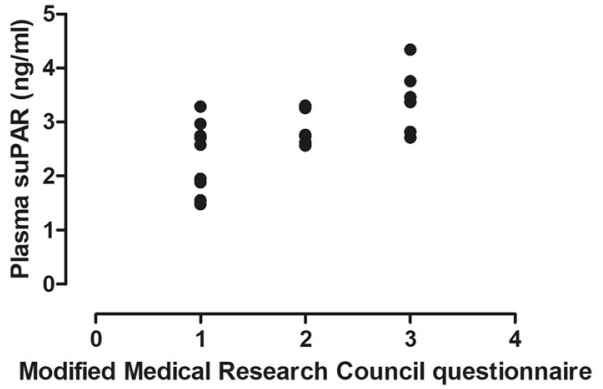

Fig. 4 Relationship between plasma suPAR levels and symptoms burden. A significant relationship was detected between plasma suPAR levels and mMRC score $(r=0.55, p<0.01)$ 
Table 3 Comparison of measures of blood pressure and arterial stiffness between COPD and controls

\begin{tabular}{lllr}
\hline & COPD $(n=24)$ & Controls $(n=18)$ & $p$ value \\
\hline SBPbr (mmHg) & $135 \pm 12.4$ & $130 \pm 9.6$ & 0.18 \\
DBP (mmHg) & $85 \pm 10.9$ & $77 \pm 7.3$ & $\mathbf{0 . 0 2}$ \\
HR (min) & $72 \pm 16$ & $69 \pm 13.7$ & 0.59 \\
PP (mmHg) & $53.5 \pm 10.5$ & $51.6 \pm 6.4$ & 0.50 \\
SBPao (mmHg) & $143 / 106-156 /$ & $123 / 98-148 /$ & $<\mathbf{0 . 0 1}$ \\
SBPao-SBPbr (mmHg) & $4 /-16$ to $11 /$ & $-4 /-11$ to $7 /$ & $<\mathbf{0 . 0 1}$ \\
Aix\% & $10.1 \pm 30.6$ & $-7.4 \pm 20.3$ & 0.06 \\
ED (ms) & $308.5 \pm 36.5$ & $320.6 \pm 28.7$ & 0.25 \\
PWVao (m/s) & $10.6 \pm 1.9$ & $8.8 \pm 1.3$ & $<\mathbf{0 . 0 1}$ \\
RT (ms) & $99.6 \pm 20.6$ & $115.2 \pm 20.2$ & $<\mathbf{0 . 0 1}$ \\
\hline
\end{tabular}

Data are expressed as mean \pm standard deviation or median /range/or percentage. Significant differences are highlighted in bold

$S B P b r$ brachial systolic blood pressure, $D B P$ brachial diastolic blood pressure, $H R$ heart rate, $P P$ pulse pressure, SBPao the central blood pressure, $S B P a o-S B P b r$ pressure amplification, Aix Augmentation Index, $E D$ ejection duration, $P W V a o$ aortic pulse wave velocity, $R T$ return time

contrast, there was no relationship between plasma suPAR levels and FVC, $\mathrm{pO}_{2}, \mathrm{pCO}_{2}, R_{\mathrm{aw}}, \mathrm{RV}, \mathrm{TLC}, \mathrm{RV} / \mathrm{TLC}$ or CAT (all $p>0.05$ ).

\section{Relationship Between Circulating suPAR and Markers of Arterial Stiffness}

Comparison of the two groups in terms of arterial stiffness is found in Table 3. There was a significant difference in SBPao, SBPao-SBPbr, PWVao and RT (all $p<0.05$ ), suggesting increased arterial stiffness in COPD.

When all subjects were investigated together, a significant correlation was seen between plasma suPAR concentrations and ejection duration $(r=-0.31, p=0.04)$, PWVao $(r=0.38, p=0.01)$ and RT $(r=-0.31, p=0.04)$, but there was no correlation with Aix\%, PP or SBPao (all $p>0.05$ ).

When only the COPD subjects were analysed, only ejection duration correlated with plasma suPAR levels $(r=-0.44, p=0.03)$.

\section{Relationship Between Circulating suPAR and IL-6, Endothelin and hsCRP}

There was a significant direct relationship between circulating suPAR concentrations and IL-6 $(r=0.45, p<0.01)$, hsCRP $(r=0.47, p<0.01)$ and endothelin-1 $(r=0.48$, $p<0.01)$ levels in all subjects. When the COPD subjects were analysed separately, plasma suPAR related to hsCRP $(r=0.53, p<0.01)$ and endothelin $(r=0.54, p<0.01)$ and tended to be related to IL-6 $(r=0.40, p=0.051)$.

\section{Discussion}

We investigated the plasma levels of suPAR, a novel biomarker of inflammation in COPD. We found elevated levels in COPD which correlated with lung function and symptom burden. A significant association was also found between increased suPAR levels and arterial stiffness, suggesting that this molecule may play a role in development of atherosclerosis in COPD.

The prevalence of cardiovascular comorbidities [23], including atherosclerosis [24] is high in COPD, and COPD is also prevalent in patients with known atherosclerosis [25]. Arterial stiffness is not only a marker of clinically symptomatic disease, but preclinical atherosclerosis as well. Recent meta-analysis reported impaired endothelial function, a surrogate for arterial stiffness in COPD [26]. This has been confirmed by our study reporting increased arterial stiffness in patients with COPD. The pathomechanism linking COPD to atherosclerosis is complex and includes common risk factors, such as smoking, pollution, male gender, and aging and systemic inflammation [24]. Pro-inflammatory cytokines, such as IL-6 or TNF- $\alpha$ are elevated in blood samples of COPD patients and can induce the release of CRP and procoagulant mediators by the liver, but have also a direct effect on endothelium [24]. IL-6 and TNF- $\alpha$ can also induce the production of suPAR from monocytes and lymphocytes [27], which has a well-established role in the development of atherosclerosis [28]. It induces cellular adhesion, leukocyte migration and eventually leads to the formation of an atherosclerotic plaque [29, 30]. Previous studies revealed that increased plasma suPAR levels were associated with risks for subclinical carotid atherosclerosis and increased occurrence of carotid plaque and cardiovascular disease [31, 32]. The prognostic value was independent from traditional risk factors (i.e., age, gender, smoking, hypertension, dyslipidemia, diabetes), and hsCRP [33, 34]. Moreover, the Monitoring Trends and Determinants in Cardiovascular Disease study compared suPAR with CRP and showed that suPAR is more related to endothelial dysfunction and atherosclerosis than CRP [35].

Circulating suPAR levels have been determined in COPD only by a few studies [12-15]. Two studies analysed suPAR during acute exacerbations $[12,13]$. These events are associated with airway and systemic inflammatory responses, and not surprisingly elevated suPAR levels were found during exacerbations $[12,13]$. The results in stable disease are contradictory, as both higher [14] and similar [15] levels were found. Comparing the two studies, the most striking difference was observed in the severity of airflow limitation, as Wang et al. recruited participants with milder severity [15]. However, large COPD studies, such as COPDGene or ECLIPSE confirmed a significant relationship between 
the extent of airflow limitation and magnitude of systemic inflammation [36]. We included patients with a wide range of lung function and found a significant relationship between airflow limitation and higher suPAR levels.

The most likely explanation of increased suPAR levels in COPD is the increase in IL-6 which is in line with the literature [37]. IL-6 upregulates suPAR production [27] which was supported by a significant association between these two molecules in our study. Circulating IL-6 induces the endothelium to release chemotactic factors for leukocytes and adhesion molecules [24], and high blood levels are associated with cardiovascular comorbidities in COPD [38]. SuPAR which is also induced by IL-6, have more direct effect in formation of the atherosclerotic plaques [29, 30], and therefore, may be a more specific biomarker of endothelial dysfunction in COPD than other circulating mediators. The clinical role of using suPAR as a biomarker for cardiovascular disease has already been assessed [11]. The current study implies that this molecule can also be useful in COPD and associated atherosclerosis, however, this has to be confirmed in larger cohorts.

Apart from lung function, suPAR was associated with symptom burden measured by the Mmrc in which score reflects breathlessness in relation to physical exercise. It is likely that this association is not independent from lung function, but due to the low number of subjects we did not test this. There was a tendency for higher plasma suPAR levels in patients with frequent exacerbations. This is in line with the findings of the ECLIPSE cohort that persistent systemic inflammation is related to the frequency of exacerbations [39]. The predictive value of suPAR to detect patients with higher risk for exacerbation has to be assessed in independent cohorts. Interestingly, we did not find any association between plasma suPAR levels and blood gases, suggesting that hypoxia may not be a strong signal for suPAR production, however, this has to be tested as well.

The biggest limitation of our study was a relatively low sample size. This was based on our previous study using the same medium (EDTA-treated plasma samples) and analytical technique [22]. This sample size allowed us to explore univariate relationships between suPAR and clinical variables, however, to conclude on independency of these association, a higher sample size is warranted. A significant relationship was found between plasma suPAR concentrations and markers of arterial stiffness when all subjects were investigated, however, many of these correlations disappeared when only the COPD patients were studied. A possible explanation could be the low sample size, but more likely it is due to the relatively mild extent of atherosclerosis in these patients as we excluded those patients with a manifesting cardiovascular disease. Ejection duration was the only variable which remained significantly associated with plasma suPAR in COPD. Increased arterial stiffness decreases systolic ejection duration which is associated with impaired coronary blood flow, therefore, ED serves as an important biomarker for development of coronary artery disease [40]. The reason why suPAR correlated with this and no other markers of arterial stiffness has to be explored in further studies.

The control groups included ever and never-smoker participants. Previous studies reported higher circulating suPAR levels in smokers [41, 42] which was confirmed in this study. There were significant differences in the prevalence of smokers and smoking history between the COPD and control groups, and ever-smoker controls had lower lung function volumes and elevated markers of arterial stiffness. The inter-group difference in suPAR may partially result from smoking. Future studies should aim for control groups with a more balanced smoking history.

\section{Conclusion}

In summary, we reported higher plasma suPAR levels in COPD, which are associated with impaired lung function and increased arterial stiffness. Plasma suPAR may be a potential link between COPD and cardiovascular comorbidities, however, this and its potential biomarker role have to be investigated in further studies.

Acknowledgements Open access funding provided by Semmelweis University (SE). This work was supported by the Hungarian Respiratory Society Grant to Renáta Marietta Böcskei. The authors are very grateful to László Kőhidai and Erzsébet Sziráki for the determination of the biomarkers and Ms Victoria Dean for English corrections. Andras Bikov is supported by the NIHR Manchester BRC.

Author Contributions RMB designed and conducted the research, collected, analysed and interpreted data, performed the statistical analysis and wrote the manuscript. $\mathrm{AB}$ designed and conducted the research, interpreted the data, wrote the manuscript and critically reviewed the article. MV critically reviewed the article. BB analysed and interpreted the data. MV, MI, CA and LGy critically reviewed the article. AB analysed and interpreted the data, performed the statistical analysis and critically reviewed the article. All of the authors read and approved the final manuscript.

\section{Compliance with Ethical Standards}

Conflict of interest Miklós Illyés is a patent owner of the Arteriograph method and has shares in TensioMed Ltd., a company that manufactures the Arteriograph device for measuring arterial stiffness. The other authors declare no conflict of interest.

Ethical Approval All procedures performed in studies involving human participants were in accordance with the ethical standards of the institutional and/or national research committee and with the 1964 Helsinki Declaration and its later amendments or comparable ethical standards.

Informed Consent Informed consent was obtained from all individual participants included in the study. 
Open Access This article is distributed under the terms of the Creative Commons Attribution 4.0 International License (http://creativeco mmons.org/licenses/by/4.0/), which permits unrestricted use, distribution, and reproduction in any medium, provided you give appropriate credit to the original author(s) and the source, provide a link to the Creative Commons license, and indicate if changes were made.

\section{References}

1. Vogelmeier CF, Criner GJ, Martinez FJ, et al (2017) Global strategy for the diagnosis, management, and prevention of chronic obstructive lung disease 2017 Report: GOLD executive summary. Eur Respir J. https://doi.org/10.1183/13993003.00214-2017

2. Barnes PJ, Burney PG, Silverman EK, Celli BR, Vestbo J, Wedzicha JA, Wouters EF (2015) Chronic obstructive pulmonary disease. Nat Rev Dis Primers 1:15076. https://doi.org/10.1038/ nrdp. 2015.76

3. Bourdin A, Burgel PR, Chanez P, Garcia G, Perez T, Roche N (2009) Recent advances in COPD: pathophysiology, respiratory physiology and clinical aspects, including comorbidities. Eur Respir Rev 18(114):198-212. https://doi.org/10.1183/09059 180.00005509

4. Coxson HO, Dirksen A, Edwards LD, Evaluation of CLtIPSEI, et al (2013) The presence and progression of emphysema in COPD as determined by CT scanning and biomarker expression: a prospective analysis from the ECLIPSE study. Lancet Respir Med 1 (2):129-136. https://doi.org/10.1016/S2213-2600(13)70006-7

5. Packard RR, Libby $P$ (2008) Inflammation in atherosclerosis: from vascular biology to biomarker discovery and risk prediction. Clin Chem 54(1):24-38. https://doi.org/10.1373/clinchem.2007.09736 0

6. Thuno M, Macho B, Eugen-Olsen J (2009) suPAR: the molecular crystal ball. Dis Markers 27(3):157-172. https://doi.org/10.3233/ DMA-2009-0657

7. Blasi F, Carmeliet P (2002) uPAR: a versatile signalling orchestrator. Nat Rev Mol Cell Biol 3(12):932-943. https://doi. org/10.1038/nrm977

8. Gustafsson A, Ajeti V, Ljunggren L (2011) Detection of suPAR in the saliva of healthy young adults: comparison with plasma levels. Biomark Insights 6:119-125. https://doi.org/10.4137/BMI.S8326

9. Donadello K, Scolletta S, Covajes C, et al (2012) suPAR as a prognostic biomarker in sepsis. BMC Med 10:2. https://doi. org/10.1186/1741-7015-10-2

10. Eugen-Olsen $\mathbf{J}$ (2011) suPAR - a future risk marker in bacteremia. J Intern Med 270(1):29-31. https://doi.org/10.111 $1 /$ j.1365-2796.2011.02372.x

11. Gozdzik W, Adamik B, Gozdzik A, et al (2014) Unchanged plasma levels of the soluble urokinase plasminogen activator receptor in elective coronary artery bypass graft surgery patients and cardiopulmonary bypass use. PLoS ONE 9(6):e98923. https ://doi.org/10.1371/journal.pone.0098923

12. Gumus A, Altintas N, Cinarka H, et al (2015) Soluble urokinasetype plasminogen activator receptor is a novel biomarker predicting acute exacerbation in COPD. Int J Chron Obstruct Pulmon Dis 10:357-365. https://doi.org/10.2147/COPD.S77654

13. AboEl-Magd GH, Mabrouk MM (2018) Soluble urokinase-type plasminogen activator receptor as a measure of treatment response in acute exacerbation of COPD. J Bras Pneumol 44(1):36-41. https://doi.org/10.1590/S1806-37562017000000151

14. Can U, Guzelant A, Yerlikaya FH, et al (2014) The role of serum soluble urokinase-type plasminogen activator receptor in stable chronic obstructive pulmonary disease. J Investig Med 62(7):938943. https://doi.org/10.1097/JIM.0000000000000105
15. Wang H, Yang T, Li D, et al (2016) Elevated circulating PAI-1 levels are related to lung function decline, systemic inflammation, and small airway obstruction in chronic obstructive pulmonary disease. Int J Chron Obstruct Pulmon Dis 11:2369-2376. https:// doi.org/10.2147/COPD.S107409

16. Miller MR, Hankinson J, Brusasco V, et al (2005) Standardisation of spirometry. Eur Respir J 26(2):319-338. https://doi. org/10.1183/09031936.05.00034805

17. Horvath IG, Nemeth A, Lenkey Z, et al (2010) Invasive validation of a new oscillometric device (arteriograph) for measuring augmentation index, central blood pressure and aortic pulse wave velocity. J Hypertens 28(10):2068-2075. https://doi.org/10.1097/ HJH.0b013e32833c8a1a

18. Baulmann J, Schillings U, Rickert S, et al (2008) A new oscillometric method for assessment of arterial stiffness: comparison with tonometric and piezo-electronic methods. J Hypertens 26(3):523-528. https://doi.org/10.1097/HJH.0b013e3282f314f7

19. Nemeth Z, Moczar K, Deak G (2002) Evaluation of the tensioday ambulatory blood pressure monitor according to the protocols of the British Hypertension Society and the Association for the Advancement of Medical Instrumentation. Blood Press Monit 7(3):191-197

20. Sugawara J, Hayashi K, Yokoi T, et al (2008) Age-associated elongation of the ascending aorta in adults. JACC Cardiovasc Imaging 1(6):739-748. https://doi.org/10.1016/j.jcmg.2008.06.010

21. Faul F, Erdfelder E, Buchner A, et al (2009) Statistical power analyses using $\mathrm{G}^{*}$ Power 3.1: tests for correlation and regression analyses. Behav Res Methods 41(4):1149-1160. https://doi. org/10.3758/brm.41.4.1149

22. Ivancso I, Toldi G, Bohacs A, et al (2013) Relationship of circulating soluble urokinase plasminogen activator receptor (suPAR) levels to disease control in asthma and asthmatic pregnancy. PLoS ONE 8(4):e60697. https://doi.org/10.1371/journal.pone.0060697

23. Bikov A, Horvath A, Tomisa G, et al.2018) Changes in the burden of comorbidities in patients with COPD and Asthma-COPD Overlap according to the GOLD 2017 Recommendations. Lung. https://doi.org/10.1007/s00408-018-0141-7

24. Bhatt SP, Dransfield MT (2013) Chronic obstructive pulmonary disease and cardiovascular disease. Transl Res 162(4):237-251. https://doi.org/10.1016/j.trsl.2013.05.001

25. Tuleta I, Farrag T, Busse L, et al (2017) High prevalence of COPD in atherosclerosis patients. Int J Chron Obstruct Pulmon Dis 12:3047-3053. https://doi.org/10.2147/copd.S141988

26. Ambrosino P, Lupoli R, Iervolino S, et al (2017) Clinical assessment of endothelial function in patients with chronic obstructive pulmonary disease: a systematic review with meta-analysis. Internal Emerg Med 12(6):877-885. https://doi.org/10.1007/s1173 9-017-1690-0

27. Larsen FF, Petersen JA (2017) Novel biomarkers for sepsis: a narrative review. Eur J Internal Med 45:46-50. https://doi. org/10.1016/j.ejim.2017.09.030

28. Pawlak K, Mysliwiec M, Pawlak D (2008) The urokinase-type plasminogen activator/its soluble receptor system is independently related to carotid atherosclerosis and associated with CCchemokines in uraemic patients. Thromb Res 122(3):328-335. https://doi.org/10.1016/j.thromres.2007.10.017

29. Fuhrman B (2012) The urokinase system in the pathogenesis of atherosclerosis. Atherosclerosis 222(1):8-14. https://doi. org/10.1016/j.atherosclerosis.2011.10.044

30. Steins MB, Padro T, Schwaenen C, Ruiz S, Mesters RM, Berdel WE, Kienast J (2004) Overexpression of urokinase receptor and cell surface urokinase-type plasminogen activator in the human vessel wall with different types of atherosclerotic lesions. Blood Coagul Fibrinolysis 15(5):383-391

31. Sehestedt T, Lyngbaek S, Eugen-Olsen J, et al (2011) Soluble urokinase plasminogen activator receptor is associated with 
subclinical organ damage and cardiovascular events. Atherosclerosis 216(1):237-243. https://doi.org/10.1016/j.atherosclerosis .2011 .01 .049

32. Persson M, Ostling G, Smith G, et al (2014) Soluble urokinase plasminogen activator receptor: a risk factor for carotid plaque, stroke, and coronary artery disease. Stroke 45(1):18-23. https:// doi.org/10.1161/strokeaha.113.003305

33. Sorensen MH, Gerke O, Eugen-Olsen J, et al (2014) Soluble urokinase plasminogen activator receptor is in contrast to high-sensitive C-reactive-protein associated with coronary artery calcifications in healthy middle-aged subjects. Atherosclerosis 237(1):60-66. https://doi.org/10.1016/j.atherosclerosis.2014.08.035

34. Hodges GW, Bang CN, Wachtell K, et al (2015) suPAR: a new biomarker for cardiovascular disease? Can J Cardiol 31(10):12931302. https://doi.org/10.1016/j.cjca.2015.03.023

35. Lyngbaek S, Sehestedt T, Marott JL, et al (2013) CRP and suPAR are differently related to anthropometry and subclinical organ damage. Int J Cardiol 167(3):781-785. https://doi.org/10.1016/j. ijcard.2012.03.040

36. Zemans RL, Jacobson S, Keene J, et al (2017) Multiple biomarkers predict disease severity, progression and mortality in COPD. Respir Res 18(1):117. https://doi.org/10.1186/s12931-017-0597-7

37. Dickens JA, Miller BE, Edwards LD, et al (2011) COPD association and repeatability of blood biomarkers in the ECLIPSE cohort. Respir Res 12:146. https://doi.org/10.1186/1465-9921-12-146
38. Miller J, Edwards LD, Agusti A, et al (2013) Comorbidity, systemic inflammation and outcomes in the ECLIPSE cohort. Respir Res 107(9):1376-1384. https://doi.org/10.1016/j. rmed.2013.05.001

39. Agusti A, Edwards LD, Rennard SI, et al (2012) Persistent systemic inflammation is associated with poor clinical outcomes in COPD: a novel phenotype. PLoS ONE 7(5):e37483. https://doi. org/10.1371/journal.pone.0037483

40. O'Rourke MF, Hashimoto J (2007) Mechanical factors in arterial aging: a clinical perspective. J Am Coll Cardiol 50(1):1-13. https ://doi.org/10.1016/j.jacc.2006.12.050

41. Botha S, Fourie CM, Schutte R, et al (2014) Associations of suPAR with lifestyle and cardiometabolic risk factors. Eur J Clin Investig 44(7):619-626. https://doi.org/10.1111/eci.12278

42. Eugen-Olsen J, Ladelund S, Sorensen LT (2016) Plasma suPAR is lowered by smoking cessation: a randomized controlled study. Eur J Clin Investig 46(4):305-311. https://doi.org/10.1111/eci.12593

Publisher's Note Springer Nature remains neutral with regard to jurisdictional claims in published maps and institutional affiliations. 